Ahmed H. Al-Salem* FRCSI FICS, Yaw Adu-Gyamfi† fFarCS FwACS, Chris S. Grant* FRCS

\title{
Congenital lobar emphysema
}

This paper reviews three cases of congenital lobar emphysema from Saudi Arabia, seen over a period of three years. All were boys aged 2.5, 7 and 8 months, and recurrent attacks of chest infection, which started during the early neonatal period, were the main presentation. In all cases, diagnosis was confirmed by chest $x$-ray. Two of them had a lobectomy and made a good recovery. Operation was refused in the third. The clinicopathological features, diagnosis and management are discussed. An outline of the anaesthetic management is also discussed briefly.

On revoit trois cas d'emphysème lobaire congénital, vus dans une période de trois ans. Tous étaient des garçons âgés de $2.5,7$ et 8 mois, avec des épisodes récurrents d'infection pulmonaire qui ont commencé tôt dans la période néonatale. Dans tous les cas, le diagnostic fut confirmé par le rayon-x pulmonaire. Deux ont eu une lobectomie et ont bien récupéré. L'opération fut refusée par le troisième. Les critères clinicopathologigues, le diagnostic et la conduite sont discutés. Une revue de la conduite anesthésiques est aussi discutée brièvement.

Congenital lobar emphysema, a comparatively rare cause of respiratory distress during infancy, is characterized by over-expansion of the affected lobe of the lung, most commonly the left upper lobe or the right middle lobe. ${ }^{1-3}$ It tends to have a progressive course and should be suspected in infants with respiratory distress or in those with repeated episodes of chest infection. Once suspected, the diagnosis can be confirmed by a plain chest $x$-ray. Appropriate surgical therapy is usually curative. ${ }^{1-6}$

We would like to draw attention to this rare condition by reporting three cases and discussing their clinical

\section{Key words}

ANAESTHESIA: thoracic, paediatric; GENETIC FACTORS: lobar emphysema; LUNG: diseases, congenital lobar emphysema, respiratory distress;

SURGERY: thoracic, lobectomy.

From the Departments of Surgery* and Anaesthesiology $\dagger$ King Fahd Hospital of the University Al Khobar, Saudi Arabia.

Address correspondence to: Dr. A. H. Al-Salem, P.O. Box 6078, Dammam 31442, Saudi Arabia. features and management. An outline of the anaesthetic management is briefly discussed.

\section{Case reports}

Three cases of congenital lobar emphysema were treated at King Fahd Hospital of the University, Al Khobar, Saudi Arabia, over a period of three years. All were boys, and their ages were two and a half, seven, and eight months. They presented with recurrent attacks of chest infection, which started during the early neonatal period, and continued to recur until their presentation. Each received several forms of medical treatment in the form of antibiotics, chest physiotherapy, bronchodilators, and oxygen therapy, without benefit. None had associated cardiac or other anomalies. In all cases, chest $x$-ray was diagnostic of congenital lobar emphysema (Figure). The left upper lobe was affected in two patients, and the right upper lobe in the third.

Two patients underwent lobectomy. Operation was refused in the third. On anaesthetic evaluation, the ASA physical status was assessed as Class IV in view of the recurrent chest infection, dyspnoea, hyperinflation of the affected lobe with mediastinal shift. Preoperative evaluation included chest $x$-ray, complete blood count, serum electrolytes, ECG, and arterial blood gas measurements. Preoperatively, the patients received antibiotics and chest physiotherapy.

Induction of anaesthesia was with halothane in 100 per cent oxygen using an Ayres T-piece circuit. Intravenous infusion of dextrose five per cent in 0.225 saline was commenced to run at a rate of $10 \mathrm{ml} \cdot \mathrm{kg}^{-1} \cdot \mathrm{hr}^{-1}$, and tracheal intubation was performed after spraying the cords and trachea with four per cent xylocaine. The patients were given meperidine $1 \mathrm{mg} \cdot \mathrm{kg}^{-1} \mathrm{IV}$ and allowed to breathe spontaneously one per cent halothane in 100 per cent oxygen, with occasional ventilatory assistance until the chest was opened. The patients were then given pancuronium $0.08 \mathrm{mg} \cdot \mathrm{kg}^{-1}$ and the lungs were ventilated with the Ohio infant ventilator with a tidal volume of $10 \mathrm{ml} \cdot \mathrm{kg}^{-1}$, and at a rate of $25 \cdot \mathrm{min}^{-1}$. When the emphysematous lobe was removed, the fresh gas flow was changed to 0.5 per cent halothane in three liters oxygen and three liters nitrous oxide. For maintenance of anaesthesia, supplementation of analgesia was with $0.5 \mathrm{mg}$. $\mathrm{kg}^{-1}$ meperidine hourly. Muscle relaxation was maintained with a quarter of the initial dose of pancuronium, 


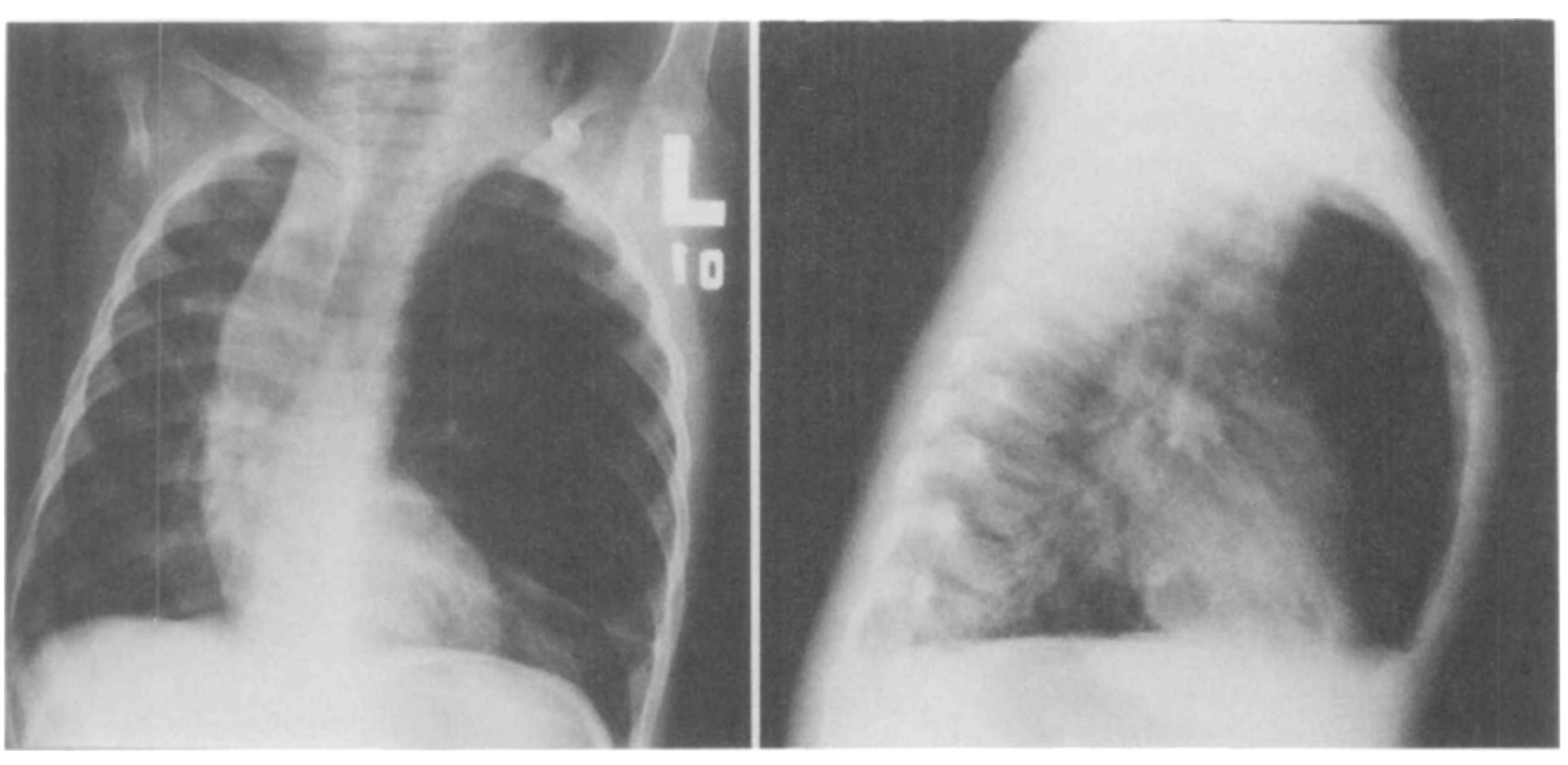

FIGURE Postero-anterior and lateral chest $x$-rays showing lobar hyperinflation and mediastinal shift

when indicated using a Bard Biomedical peripheral nerve stimulator 750 digital for neuromuscular monitoring. There was continuous ECG monitoring. Blood pressure and heart rate were monitored with a Dinamap, and were stable throughout surgery. Body temperature was continuously monitored with a rectal probe and displayed. The body temperature was maintained at $36-37^{\circ} \mathrm{C}$ throughout surgery with a thermal blanket. The end-tidal $\mathrm{PO}_{2}$ and $\mathrm{PCO}_{2}$ were monitored continuously with a Datex Normocap. The end-tidal $\mathrm{PCO}_{2}$ ranged between 30 and $35 \mathrm{mmHg}$, and $\mathrm{PO}_{2}$ between 70 and $80 \mathrm{mmHg}$ on 100 per cent oxygen.

At the end of surgery, and before closure of the chest, intercostal block was performed by the surgeon under direct vision. Using 0.5 per cent bupivacaine, $2 \mathrm{ml}$ were injected into the intercostal spaces above and below, and into the intercostal space of surgery. Muscle relaxation was reversed with neostigmine $0.04 \mathrm{mg} \cdot \mathrm{kg}^{-1}$, and atropine $0.02 \mathrm{mg} \cdot \mathrm{kg}^{-1}$, the tracheas were extubated in the operating room, and the patient allowed to breathe spontaneously. Postoperatively, they were monitored in the intensive care unit with ECG, chest $x$-ray, and blood gas analyses. The chest drains were removed when there was full expansion of the remaining lobes of the lungs and if there was no or minimal drainage.

Histological examination of resected specimens showed markedly distended alveoli and elongated cystic spaces. Both patients made a rapid recovery without complications. Follow-up chest $x$-ray showed re-expansion of the remaining lobes to fill the space created by lobectomy.

\section{Discussion}

Congenital lobar emphysema (CLE) is a rare cause of respiratory distress during infancy which is cured by surgery. It is more common among males than females. It is usually unilateral, affecting the left upper lobe, followed by the right middle lobe, although bilateral involvement has been reported. ${ }^{4,7}$

The aetiology of congenital lobar emphysema is unknown. The current theory, which suggests inadequate cartilaginous support of the bronchus, was first proposed by Gross and Lewis, ${ }^{8}$ and is the most favoured. ${ }^{2,3.9}$ Polyalveolar lobe (an estimated three- to five-fold increase in the alveolar number for the whole lobe), described first by Hislop and Reid, is one of the recently described pathological entities that can give rise to CLE. ${ }^{10}$

The severity of symptoms of CLE vary. Myers ${ }^{6}$ described three clinical groups: (1) CLE in infancy; (2) symptomatic CLE in older children; and (3) asymptomatic (discovered incidentaly) CLE. Our patients were two and a half, seven, and eight months of age, and had symptoms dating from the early neonatal period. The association of CLE with congenital heart disease, which is present in 12-14 per cent of patients, is well known. ${ }^{2.4}$

Once suspected, the diagnosis of CLE can be confirmed by postero-anterior and lateral chest $x$-rays (Figure), which show the classical signs of lobar hyperinflation, mediastinal shift, and, sometimes, contralateral and ipsilateral atelectasis. The ipsilateral lower lobe becomes compressed and atelectatic and can be seen on $x$-rays as a 
small, triangular density along the lower cardiac border. Sometimes the hyperinflated lobe herniates to the opposite side (Figure). The presence of bronchovascular markings in the hyperinflated lobe helps differentiate CLE from pneumothorax, a condition with which it is commonly confused. Bronchoscopy and bronchography are usually unnecessary and may be associated with morbidity and mortality. ${ }^{4.6}$ Bronchoscopy may be of value in ruling out the presence of intraluminal foreign bodies causing either obstructive emphysema or atelectasis with compensatory emphysema. May and his associates advocate that bronchoscopy be carried out in the operating room, and preparation made for immediate thoracotomy.

Congenital lobar emphysema usually follows a progressive course. If not recognized and treated, it may be fatal. Despite reports of successful conservative management, ${ }^{11}$ the accepted treatment is surgical lobectomy of the affected lobe, which is usually curative. During thoracotomy, the infant is at greatest risk on induction of anaesthesia, because if positive pressure ventilation is applied before opening the chest, it may cause rapid inflation of the emphysematous lobe with sudden mediastinal shift and cardiac arrest. Thus, induction of anaesthesia should provide adequate spontaneous ventilation with minimal airway pressure. It has been suggested that general anaesthesia be supplemented with local anaesthesia until the chest is opened, and the emphysematous lobe is delivered. ${ }^{4}$ Thereafter, the patient can be paralyzed, and the lungs ventilated. Hyperinflation of the emphysematous lobe should be prevented by avoiding the use of nitrous oxide before the affected lobe is excised, as $\mathrm{N}_{2} \mathrm{O}$ will accumulate in the affected lobe leading to its expansion. In our patients, nitrous oxide was added to the gas mixture only after excision of the emphysematous lobe. Cardiopulmonary monitoring, including continuous ECG, heart rate, blood pressure, end-tidal $\mathrm{PO}_{2}$ and $\mathrm{PCO}_{2}$ measurement and pulse oximetry, is mandatory for these patients. Pulse oximetry was not used in these patients because facilities were not available at the time of surgery.

\section{References}

1 Murray GF. Congenital lobar emphysema. Surg Gynecol Obstet 1967; 124: 611-25.

2 Raynor AC, Cap MP, Sealy WC. Lobar emphysema of infancy; diagnosis, treatment and etiological aspects. Ann Thorac Surg 1967; 4: 374-85.

3 Rickham PP, Lister J, Irving IM. Neonatal Surgery. 2nd ed. London: Butterworth, 1978, 215-9.

4 Hendren WH, McKee DM. Lobar emphyscma of infancy. J Pediatr Surg 1966; 1: 24-9.

5 Leape $L L$, Longino LA. Infantile lobar emphysema. Pediatrics $1964 ; 34:$ 246-55.

6 Myers NA. Congenital lobar emphyscma. Aust NZ J Surg 1969; 30: 32-5.

7 May RL, Meese EH, Times JJ. Congenital lobar emphysema: case report of bilateral involvement. J Thorac Cardiovasc Surg 1964; 48: 850-4.

8 Gross $R E$, Lewis $J E$. Defect of the anterior mediastinum. Surg Gynecol Obstet 1945; 80: 549-54.

9 Rickham FC, Rosenkrantz JG. Thoracic surgical problems in infancy and childhood; congenital lobar emphysema. Surg Clin North Am 1985; 65: 1434-6.

10 Tapper D. Schuster S, McBride J et al. Polyalveolar lobe anatomic and physiological parameters and their relationship to congenital lobar emphysema. J Pediatr Surg 1980; 15: 931-7.

11 Korngold $H W$, Baker $J M$. Nonsurgical treatment of unilobar obstructive emphysema of the newborn. Pediatrics 1954, 14: 296. 